\title{
AVALIAÇÃO DA FRAGILIDADE AMBIENTAL DA BACIA HIDROGRÁFICA DO RIO UNA (ESTADO DA BAHIA) COMO SUBSÍDIO PARA O PLANEJAMENTO E A GESTÃO TERRITORIAL
}

\author{
Gabriel Paternostro LISBOA ${ }^{1}$ \\ Mauricio Santana MOREAU \\ Ronaldo Lima GOMES \\ Maria Eugênia Bruck de MORAES ${ }^{4}$
}

\section{Resumo}

Em decorrência da crise na lavoura cacaueira, a partir do final da década de 80 , intensas modificações ocorreram no uso e ocupação do solo da bacia do rio Una, sem um adequado planejamento territorial. Diante desse contexto e, em função da quase inexistência de dados sobre essa bacia, este artigo tem por objetivo apresentar uma avaliação das fragilidades natural e ambiental da mesma, no intuito de subsidiar o planejamento e a gestão da área. Para tanto, foram caracterizados os sistemas físicoambientais da bacia, inicialmente com base na abordagem analítica e, posteriormente, seguindo a abordagem sistêmica, para se chegar à compreensão do todo, em virtude da complexidade das inter-relações que se estabelecem entre esses sistemas numa escala espaço-temporal. A área de estudo está localizada no Sul do Estado da Bahia, abrangendo uma área de $1.760,30 \mathrm{~km}^{2}$. Os procedimentos metodológicos adotados foram desenvolvidos com o apoio de técnicas de geoprocessamento. Como resultado, verificou-se que a declividade é um índice controlador nos processos erosivos da bacia, por possuir $81,21 \%$ da área com relevos acentuados. Porém, se tratando de regiões próximas ao litoral, as classes pedológicas e litológicas foram mais decisivas, em função da predominância de sedimentos inconsolidados.

Palavras-chave: Sistema de Informação Geográfica. Capacidade Física do Solo. Fragmentação. Mata Atlântica.

\footnotetext{
${ }^{1}$ Universidade Estadual de Santa Cruz (UESC), Mestre em Desenvolvimento Regional e Meio Ambiente pelo Programa de Pós-Graduação em Desenvolvimento e Meio Ambiente (PPGDMA), Rua: Né Abade, nº 84, Bairro: Pontalzinho, Itabuna/BA. E-mail: gabrielpaternostro@hotmail.com

2 UESC, Professor Pleno do Departamento de Ciências Agrárias e Ambientais (DCAA), Rod. Jorge Amado, km 16, Bairro: Salobrinho, Ilhéus/BA. E-mail: mmoreau@uesc.br

${ }^{3}$ UESC, Professor Titular do Departamento de Ciências Agrárias e Ambientais (DCAA) e do PPGDMA, Rod. Jorge Amado, km 16, Bairro: Salobrinho, Ilhéus/BA. E-mail: rlgomes@uesc.br

4 UESC, Professora Plena do Departamento de Ciências Agrárias e Ambientais (DCAA) e do PPGDMA, Rod. Jorge Amado, km 16, Bairro: Salobrinho, Ilhéus/BA. E-mail: eugeniabruck@uesc.br
} 


\section{Abstract}

\section{Environmental fragility evaluation of Una river hydrographic basin - aliança, Bahia, as allowance for planning and territorial management}

As a result of the crisis that hit cocoa plantation from the late 80 , are observed intense changes regarding the use and occupation of the land around Una River Hydrographic Basin (BHRU) without proper environmental planning. Thus, this project aimed to study the contents of Natural and Environmental Fragility of the basin, through Ross methodology (1994), in order to know their strengths and vulnerabilities, and providing support to the planning and management of the area. For this, they were characterized existing physical-environmental systems to reach the understanding of the whole, paying attention to the complexity that these interrelationships present in the relationship space-time. The study area is located in the southern of Bahia, covering an area of 1760.30 square kilometers. The adopted methodological procedures have used geoprocessing techniques because they are important tools for geo-environmental studies. As a result, it was found that the slope is a controller in the erosion rate of the basin, to possess $81.21 \%$ of the area marked with reliefs. But when it comes to near the coast regions, soil and lithological classes were more decisive, due to the predominance of unconsolidated sediments. In the basin, there were $29.31 \%$ of areas with environmental fragility ranging from medium to very high.

Key words: Geographic Information System. Land use. Forest remnants.

\section{INTRODUÇÃO}

Atualmente, acreditando-se no seu caráter integrador, muitos planejadores e gestores ambientais têm adotado o uso de Bacias Hidrográficas em trabalhos que visam o manejo dos recursos naturais, bem como o planejamento do território e a gestão das atividades antrópicas. Além disso, as bacias são formadas por um mosaico de subsistemas integrados estruturalmente e funcionalmente, onde os processos bióticos e abióticos se desenvolvem, apresentando as condições ideais para o desenvolvimento de estudos voltados à conservação e preservação do meio ambiente.

Desta forma, muitas são as possibilidades de análise a serem realizadas sobre bacias hidrográficas. Para um adequado planejamento territorial, o uso do Sistema de Informações Geográficas (SIG) aliado aos princípios do sensoriamento remoto e a aplicação de ferramentas de geoprocessamento são de extrema utilidade para o desenvolvimento desse tipo de pesquisa.

O SIG é um sistema informatizado composto por um conjunto de ferramentas computacionais capazes de armazenar, manipular e representar os dados espacialmente. Assim, o sistema possui um papel fundamental em estudos que abordem questões ecológicas, principalmente aquelas que apresentam um componente espacial e que envolvem interações em múltiplas escalas.

A bacia do rio Una, até o final da década de 80 , possuía sua economia baseada na produção e exportação do cacau (Theobroma cacao), cultivado através do "sistema cabruca" que consiste na plantação do cacau utilizando-se a sombra do dossel da floresta (SAMBUICHI et al., 2012; SOLLBERG, SCHIAVETTI, MORAES, 2014).

Porém, devido à disseminação do fungo "vassoura-de-bruxa" (Crinipellis perniciosa), às oscilações climáticas e ao baixo valor econômico do produto no mercado internacional, a região passou por uma profunda crise, adotando práticas agrícolas 
não sustentáveis e transformando a paisagem com o desmatamento das áreas de cabruca que foram parcialmente substituídas por pastagens.

Apesar dos inúmeros conflitos gerados na região, a BHRU, revela-se como um espaço territorial ambientalmente importante, por ainda resguardar remanescentes florestais do bioma Mata Atlântica que apresenta elevada biodiversidade, além de muitas espécies endêmicas (THOMAS et al., 1998).

Diante desse panorama e das poucas informações disponíveis sobre a BHRU, acredita-se ser de relevante importância o estudo geoambiental aqui apresentado, com a identificação das áreas de maior fragilidade frente às atividades antrópicas. Assim, a metodologia proposta por Ross (1994) para avaliar a fragilidade natural e ambiental do terreno, fundamentada no conceito de "unidade ecodinâmica" preconizado por Tricart (1977), foi adotada no desenvolvimento deste estudo, por justamente permitir a identificação dessas áreas de maior fragilidade.

No Brasil, a aplicação de tal metodologia em bacias hidrográficas já foi utilizada com sucesso, como exemplo pode-se citar o trabalho de Gomes (2013), que teve como objetivo avaliar as fragilidades ambientais e vulnerabilidade à perda de solo em área da Bacia do Rio Almada, localizada na Região Sul do Estado da Bahia. Logo, o presente estudo apresenta os resultados obtidos a partir da avaliação das fragilidades natural e ambiental da BHRU, ainda inéditos para esta área de estudo.

\section{METODOLOGIA}

Área de estudo

A Bacia Hidrográfica do Rio Una (BHRU) localiza-se no sul do estado da Bahia, especificamente na parte leste da região cacaueira. A mesma possui uma área total de $1.760,30 \mathrm{~km}^{2}$, abrangendo os municípios de Una, Santa Luzia, Arataca, São José da Vitória, Buerarema, Jussari, Camacan e Mascote (Tabela 1 e Figura 1).

\section{Tabela 1 - Área total, absoluta e relativa ocupada pelos municípios na Bacia Hidrográfica do Rio Una}

\begin{tabular}{lccc}
\hline Municípios & Município - $\mathbf{k m}^{\mathbf{2}}$ & Área na bacia - $\mathbf{k m}^{\mathbf{2}}$ & Área na bacia - \% \\
\hline Arataca & 435,63 & 427,85 & 24,31 \\
Buerarema & 219,31 & 5,09 & 0,29 \\
Camacan & 584,42 & 5,36 & 0,30 \\
Jussari & 328,95 & 1,46 & 0,08 \\
Mascote & 818,10 & 0,55 & 0,03 \\
Santa Luzia & 650,05 & 489,47 & 27,81 \\
São José da Vitória & 127,83 & 95,22 & 5,41 \\
Una & 1221,53 & 735,30 & 41,77 \\
\hline Total & $\mathbf{4 3 8 5 , 8 2}$ & $\mathbf{1 7 6 0 , 3 0}$ & $\mathbf{1 0 0}$ \\
\hline
\end{tabular}

De acordo com Barreto et al. (2008), a BHRU constitui um sistema sócio ecológico de ampla importância para o sul da Bahia, por apresentar uma marcante agrobiodiversidade, com variações de áreas de remanescentes florestais, pastagens, entre outros cultivos agrícolas. 


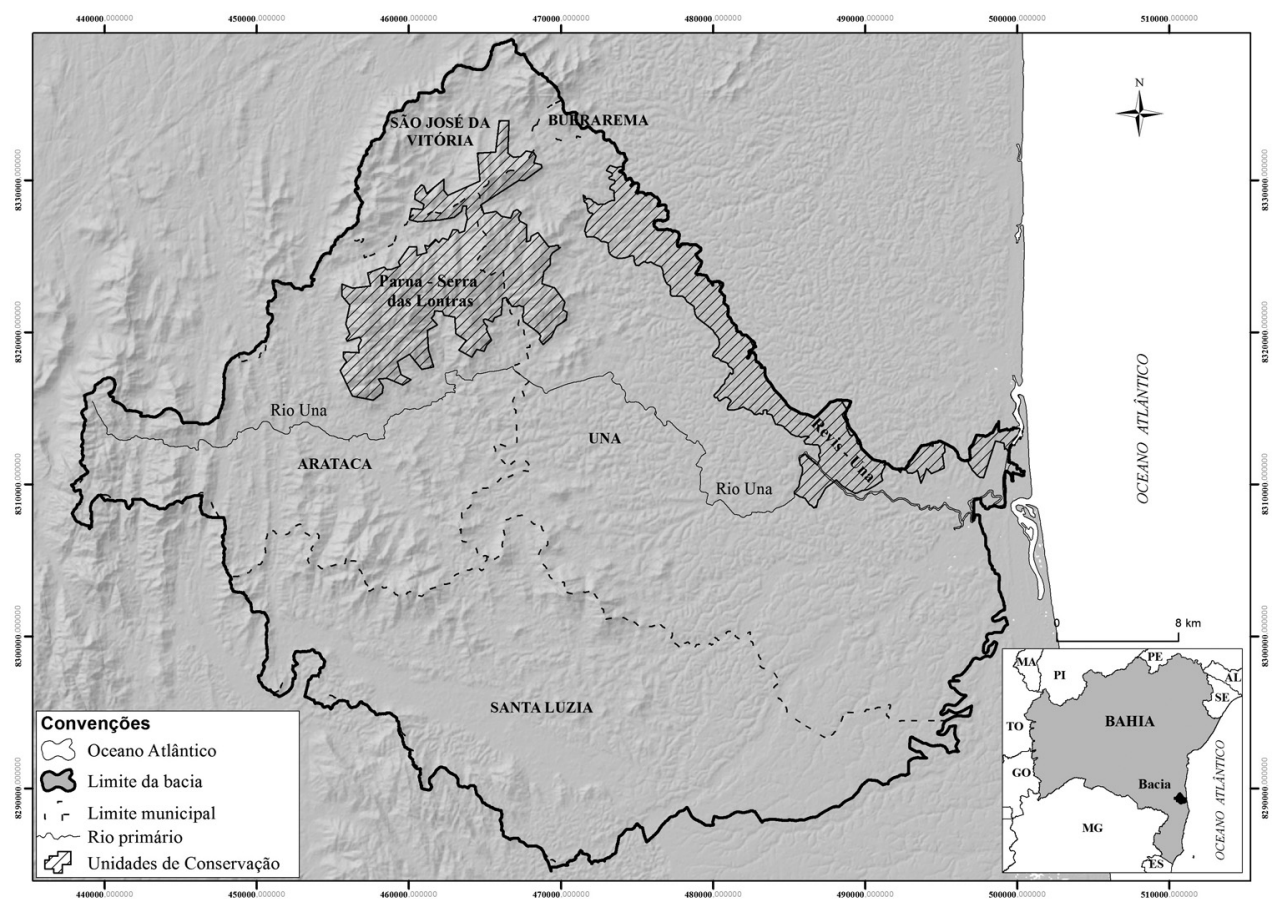

Figura 1 - Localização da Bacia Hidrográfica do Rio Una no estado da Bahia e localização dos municípios inseridos nessa bacia, integral ou parcialmente

Nos limites da BHRU estão presentes três cursos d'água principais, os rios Braço do Norte, São Pedro e Una que dá nome à bacia, também conhecida na região por bacia hidrográfica do rio Una-Aliança. Estes rios são de suma importância para a manutenção dessa bacia, visto que apresentam significativa densidade de drenagem, abrangendo em torno de $50 \%$ de sua área total, possibilitando o abastecimento de vários municípios.

Na BHRU também estão localizadas três importantes unidades de conservação, o Parque Nacional Serra das Lontras, com 113,35 km² e o Refúgio de Vida Silvestre de Una com 84,23 km², inseridos integralmente na bacia, e a Reserva Biológica de Una, inserida parcialmente, com $0,82 \mathrm{~km}^{2}$, cuja relevância para a conservação de espécies da Mata Atlântica é internacionalmente reconhecia.

\section{Procedimentos metodológicos}

A delimitação da BHRU foi realizada utilizando-se o modelo de simulação hidrológico ArcSWAT (Soil and Water Assessment Tool), associado ao SIG ArcGis versão 10.2 .

Considerando-se que a topografia é um fator preponderante nos processos de transporte e distribuição da água de uma bacia, foram usados os dados de altimetria disponíveis no Banco de Dados Geomorfométricos do Brasil (Projeto Topodata), das folhas topográficas 15S39_ZN e 15S405_ZN. 
Após o pré-processamento dos arquivos e os ajustes do Modelo Digital do Terreno (MDT), iniciou-se a delimitação da BHRU através do ArcSWAT. , tendo como referência Di Luzio et al. (2002).

Elaboração do diagnóstico dos componentes físicos e do uso e ocupação do solo da BHRU

Nesta etapa do trabalho, a presente pesquisa optou por iniciar caracterizando as diferentes distribuições hipsométricas e de declividade da bacia. Para isso, teve como base imagens topográficas (Projeto Topodata), trabalhadas em ambiente SIG.

As formas e características do substrato rochoso foram obtidas do mapa elaborado pela Companhia de Pesquisa de Recursos Minerais em parceria com Companhia Baiana de Pesquisa Mineral (CPRM\CBPM) para o Projeto Itapetinga-Canavieiras, bem como do Mapa Geológico do Quaternário Costeiro do Estado da Bahia, ambos na escala 1:250.000. Tendo em vista que a escala adotada no presente trabalho foi de $1: 100.000$, foram feitas correções nos contatos das unidades com base no MDT (Modelo Digital do Terreno) e imagens de satélite (Landsat 8/2015).

Os dados pedológicos foram obtidos no banco de dados da Superintendência de Estudos Econômicos e Sociais da Bahia (SEI), disponíveis em escala 1:500.000, o que gerou a necessidade da realização de ajustes nos contatos das classes, também realizados com base nas informações do MDT e das imagens de satélite.

Para a realização do mapeamento do uso e ocupação do solo foram utilizadas imagens de satélite Landsat 8 (2015), disponíveis no banco de dados da United States Geological Survey (USGS), com o objetivo de melhorar a qualidade das bandas multiespectrais das imagens, as quais foram fusionadas à banda Pan para se obter uma resolução de pixel de 15 × 15 metros. Assim, após o tratamento das imagens, procedeu-se a classificação supervisionada das mesmas, através do algoritmo de máxima verossimilhança do SIG e trabalhos de campo que constataram a necessidade de correções, realizadas através de edição matricial, com correções pixel a pixel. Esta técnica permitiu ajustar os resultados da classificação supervisionada.

\section{Elaboração da avaliação das fragilidades natural e ambiental da BHRU}

A metodologia utilizada para a avaliação das fragilidades natural e ambiental foi baseada no método descrito por Ross (1994). A avaliação natural de um terreno exige o levantamento das características do substrato rochoso, dos tipos de solo, das classes de declividade e dos dados de temperatura, pluviosidade e umidade do ar, enquanto que a avaliação ambiental além de considerar tais características, contempla também as características do uso e ocupação do solo. A integração e correlação dessas características, conforme apresentam as equações (1) e (2), possibilitaram a elaboração de um diagnóstico das diferentes categorias hierárquicas das fragilidades do terreno para a BHRU.

Fragilidade Natural $(F . N)=(S . R+S+D+C) / 4$

(Equação 01),

onde: $\mathrm{S} \cdot \mathrm{R}=$ Substrato Rochoso; $\mathrm{S}=$ Solos; $\mathrm{D}=$ Declividade; $\mathrm{C}=$ Clima.

Fragilidade Ambiental (F.A) $=(F . N+$ U.S $) / 2$

(Equação 02),

onde: F.N = Fragilidade Natural; U.S = Uso e Ocupação do Solo. 
Partindo destes pressupostos, o primeiro passo foi atribuir pesos às classes de cada unidade temática, tendo como base a sua suscetibilidade ambiental. Para as interpretações, o trabalho fundamentou-se nas pesquisas de Ross (1994), Waldburger (2014) e Gomes (2013), como apresentado na tabela 2. Vale ressaltar, que a atribuição de pesos referente ao clima, levou-se em consideração que a BHRU apresenta um índice constante de chuva, sem estação seca definida, desta forma possuindo valor 3,0 .

Tabela 2 - Pesos de fragilidade para os atributos avaliados na área em estudo

\begin{tabular}{|c|c|}
\hline Classes de Substrato Rochoso & Pesos \\
\hline Cobertura detrítica indiferenciada (Ndi) & 5,0 \\
\hline Complexo Buerarema (PP2bg) & 2,2 \\
\hline Complexo Buerarema (PP2bo) & 2,2 \\
\hline Complexo Ibicaraí (A34ie) & 2,2 \\
\hline Corpo de Anuri (PP2 $2 \lambda a)$ & 2,3 \\
\hline Depósitos aluvionares ( $\mathrm{N} 4 \mathrm{a}$ ) & 5,0 \\
\hline Depósitos litorâneos (N4li) & 5,0 \\
\hline Depósitos litorâneos antigos (N3li) & 5,0 \\
\hline Formação Salobro (NP3 $\varepsilon$ sa\mc) & 3,3 \\
\hline Grupo Barreiras (ENb) & 4,3 \\
\hline Grupo Rio Pardo - Formação Camacã (NP12pc) & 3,1 \\
\hline Grupo Rio Pardo - Formação Panelinha (NP12pn) & 3,2 \\
\hline Suíte Intrusiva Pau Brasil (PP2y2mp) & 2,2 \\
\hline Classes de Solos & Pesos \\
\hline Neossolos Flúvicos (Aluviais) & 4,5 \\
\hline Gleissolos Sálicos (Mangues) & 5,0 \\
\hline Espodossolos Humilúvicos Hidromórficos & 4,5 \\
\hline Argissolo Vermelho Amarelo Distrófico & 4,0 \\
\hline Argissolo Vermelho Amarelo Eutrófico & 3,0 \\
\hline Latossolo Amarelo Distrófico & 2,0 \\
\hline Latossolo Vermelho Amarelo Distrófico & 2,0 \\
\hline Classes de Declividade ( $\%$ ) & Pesos \\
\hline$<6$ & 1,0 \\
\hline $6-12$ & 2,0 \\
\hline $12-20$ & 3,0 \\
\hline $20-30$ & 4,0 \\
\hline $30>$ & 5,0 \\
\hline Classes de Uso e Ocupação do Solo & Pesos \\
\hline Pasto/Solo Exposto & 5,0 \\
\hline Remanescentes Florestais & 1,0 \\
\hline Sistema Agroflorestal - Cacau Cabruca & 1,0 \\
\hline Cultivos Diversos & 4,0 \\
\hline Áreas Úmidas & 5,0 \\
\hline Manguezais & 1,0 \\
\hline Áreas Urbanizadas & 5,0 \\
\hline
\end{tabular}




\section{RESULTADOS E DISCUSSÕES}

\section{Diagnóstico dos componentes físicos e do uso e ocupação do solo da BHRU}

A delimitação da área de estudo mostra que a mesma faz limite ao norte e oeste com a bacia do rio Cachoeira, ao sul com o rio Pardo e, ao leste com o oceano atlântico; e a partir da compartimentação da BHRU em sub-bacias, foram identificadas sete sub-bacias, denominadas em função de seus cursos d'água principais: sub-bacias do rio Una I e II, rio Braço do Norte, rio São Pedro, rio Salobro, rio Vermelho e do ribeirão das Varas (Figura 2).

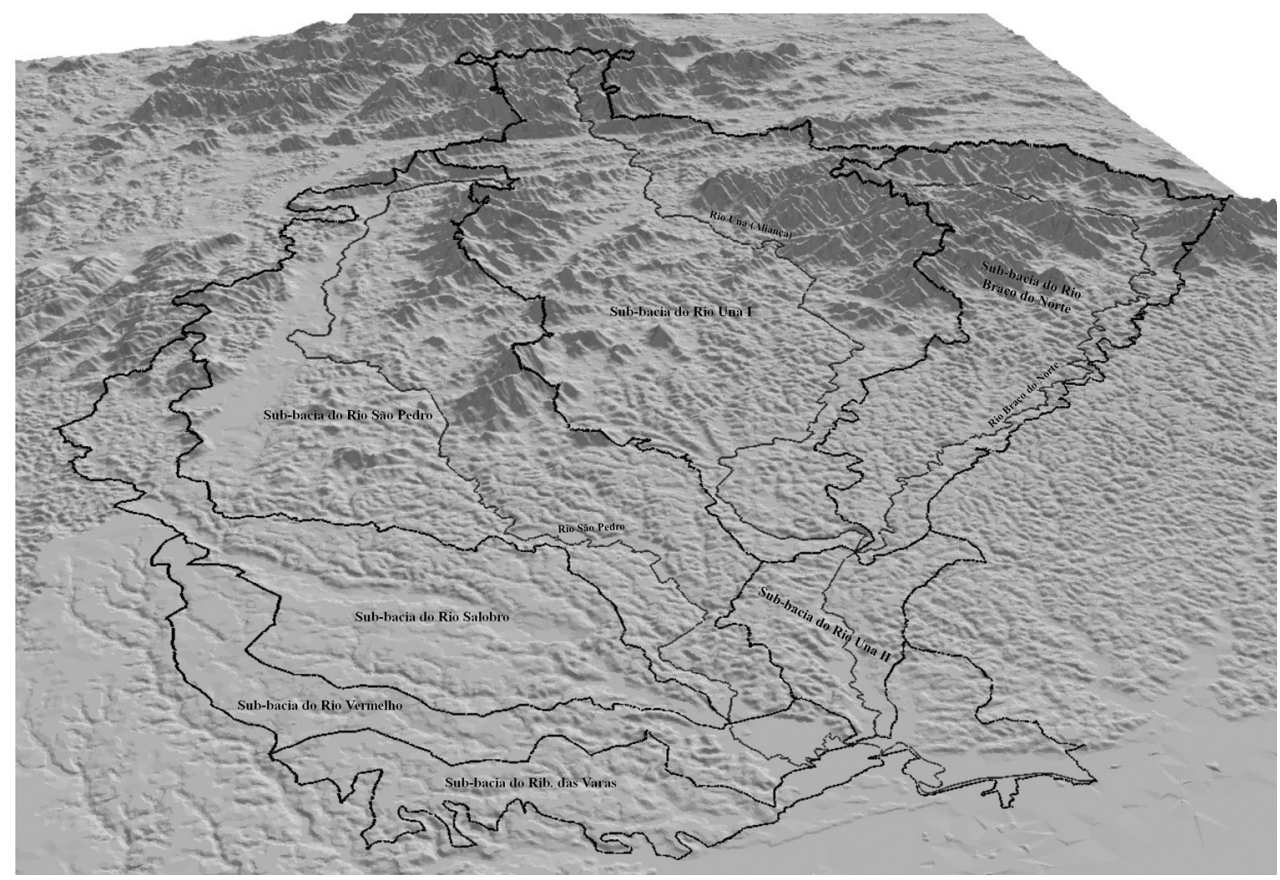

\section{Figura 2 - Modelo Digital do Terreno da BHRU, mostrando os seus limites, sub-bacias, divisores d'água e sistema de drenagem}

Seu curso d'água principal, o rio Una, tem sua nascente localizada a oeste do distrito de Anuri, no município de Arataca, em uma serra com altitude aproximada de $650 \mathrm{~m}$, vindo a desaguar ao leste do município de Una, após percorrer cerca de cem quilômetros. Em função das suas características geomorfológicas que determinam o padrão de drenagem, a BHRU apresenta padrão dendrítico. Seu comportamento de escoamento global caracteriza-se como do tipo exorreico, visto que a rede de drenagem escoa as águas de modo contínuo até o oceano (CHRISTOFOLETTI, 1974).

Aplicando-se o método de hierarquização dos cursos d'água de Strahler (1964), com auxílio do ArcGIS, constatou-se que a área de estudo possui canais de $1^{a}$ à $5^{a}$ ordem que juntos contabilizam 982,79 km de drenagem. E, a partir do cálculo das equações descritas por Mello e Silva (2013), foram obtidos os seguintes valores: coeficiente de compacidade $(2,45)$, fator de forma $(0,44)$, índice de conformação 
$(0,46)$, densidade de drenagem $\left(0,56 \mathrm{~km} / \mathrm{km}^{2}\right)$, entre outros, apresentados na tabela 3.

\section{Tabela 3 - Valores dos índices fisiográficos calculados para a BHRU}

\begin{tabular}{lcc}
\hline Classes Climatológicas & Área na Bacia - $\mathbf{~ k m}^{\mathbf{2}}$ & Área na Bacia - \% \\
\hline $\begin{array}{l}\text { Af - Clima Tropical Úmido, } \\
\text { sem estação seca }\end{array}$ & $1.721,97$ & 97,82 \\
Cfa - Clima Subtropical, & 32,61 & $\mathbf{1 , 8 5}$ \\
com verão quente & 5,72 & 0,33 \\
$\begin{array}{l}\text { Cfb - Clima Subtropical, } \\
\text { com verão temperado }\end{array}$ & $\mathbf{1 . 7 6 0 , 3 0}$ & $\mathbf{1 0 0}$ \\
\hline Total &
\end{tabular}

Quanto às características climáticas, de acordo com o sistema de classificação proposto por Köeppen e adaptado por Alvares et al. (2013) para o Brasil o clima predominante na bacia é do tipo Tropical sem estação seca, também denominado Clima tropical úmido (Af), ocorrendo também em baixa proporção, o Clima subtropical com verão quente ( $\mathrm{Cfa}$ ) em $1,85 \%$ da área de estudo e o com verão temperado (Cfb) em apenas $0,33 \%$ (Tabela 4 ). Tabela 4 - Distribuição dos tipos climáticos
encontrados na BHRU

\begin{tabular}{lccc}
\hline Classe Analisadas & Características do Relevo & Área $\mathbf{( k m}^{\mathbf{2}}$ ) & Área (\%) \\
\hline $1-10 \mathrm{~m}$ & Planície Costeira & 21,14 & 1,20 \\
$10-50 \mathrm{~m}$ & Fundos de Vales & 107,33 & 6,10 \\
$50-100 \mathrm{~m}$ & Tabuleiros Costeiros & 377,07 & 21,42 \\
$100-300 \mathrm{~m}$ & Tabuleiros Pré-Litorâneos & 936,19 & 53,18 \\
$300-1009 \mathrm{~m}$ & Planaltos Pré-Litorâneos & 318,57 & 18,10 \\
\hline Total & - & $\mathbf{1 . 7 6 0 , 3 0}$ & $\mathbf{1 0 0}$ \\
\hline
\end{tabular}

Segundo Alvares et al. (2013), esses tipos climáticos são caracterizados pela ocorrência de chuvas ao longo da maior parte do ano, com pluviosidade média mensal superior a $60 \mathrm{~mm}$ e anual, superior a $1.500 \mathrm{~mm}$. Além disso, tais autores destacam que no estado da Bahia, os subtipos do Clima subtropical são encontrados em regiões com altitudes topográficas que variam de 750 a $900 \mathrm{~m}$, sendo que o Cfa costuma apresentar como temperatura média do mês mais quente acima ou igual a $22^{\circ} \mathrm{C}$ e o $\mathrm{Cfb}$, temperatura média do mês mais quente abaixo de $22^{\circ} \mathrm{C}$.

A análise da tabela 5 e da figura 3 mostra que há uma grande variação de altitude na área de estudo, com valores que vão de 1 até $1.009 \mathrm{~m}$.

\section{Tabela 5 - Distribuição das formas de relevo e respectivas classes hipsométricas da BHRU}

\begin{tabular}{lccc}
\hline Declividade - \% & Tipo de Relevo & Área $\mathbf{( k m}^{\mathbf{2}} \mathbf{)}$ & Área (\%) \\
\hline$<6$ & Plano à Suave Ondulado & 330,72 & 18,79 \\
$6-12$ & Ondulado & 378,63 & 21,51 \\
$12-20$ & Ondulado & 400,10 & 22,73 \\
$20-30$ & Forte Ondulado & 317,08 & 18,01 \\
$30>$ & Forte Ondulado à Escarpado & 333,77 & 18,96 \\
\hline Total & - & $\mathbf{1 . 7 6 0 , 3 0}$ & $\mathbf{1 0 0}$ \\
\hline
\end{tabular}




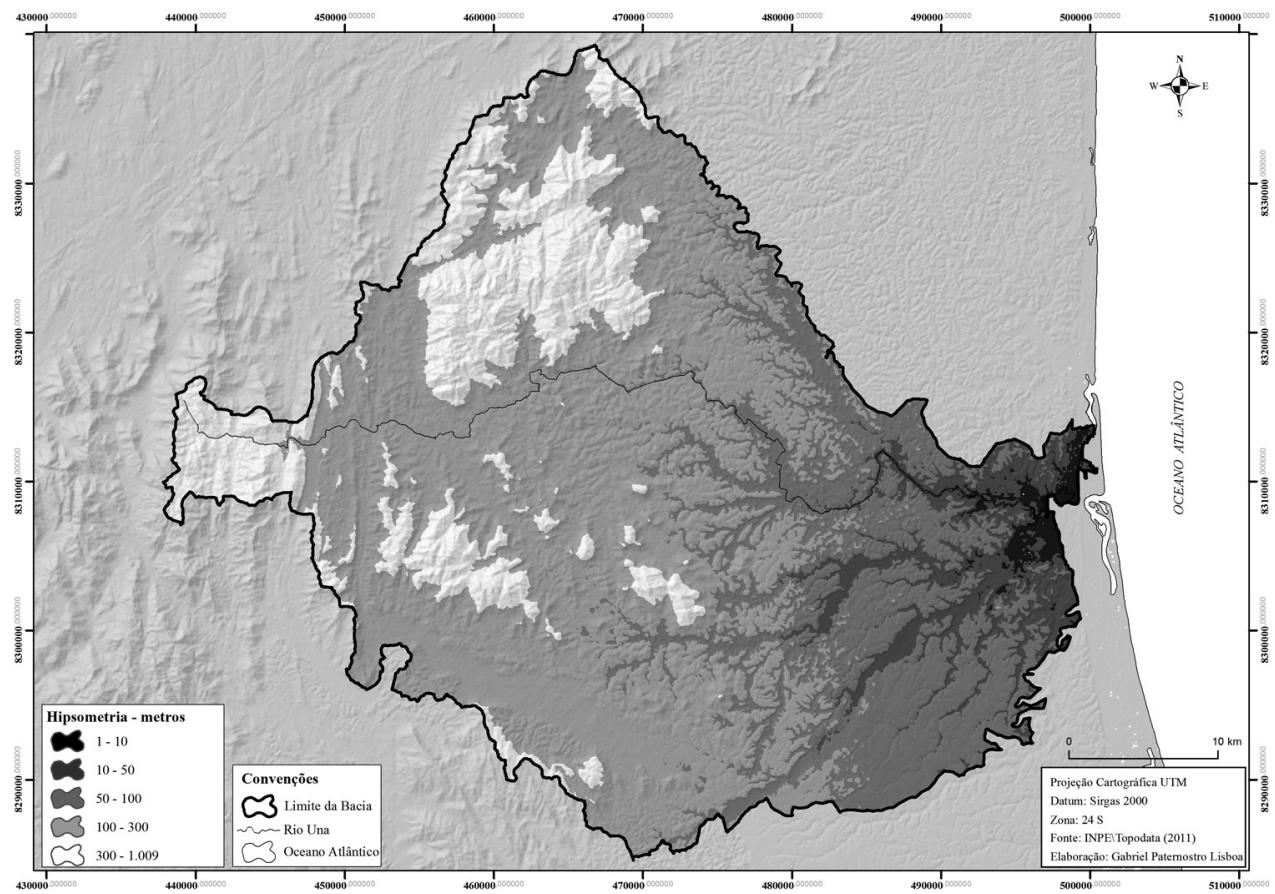

Figura 3 - Mapa Hipsométrico da Bacia Hidrográfica do Rio Una

A análise integrada dos dados obtidos com visitas in loco, constatou-se que as cotas de até $10 \mathrm{~m}$ ocorrem predominantemente na planície costeira, onde se encontram manguezais, pequenos terraços arenosos e aluviões. A classe de 10 a $50 \mathrm{~m}$ corresponde aos Fundos de vale provenientes das ações fluviais e também conhecidos como regiões de acumulação. Já as altitudes de 50 a 100 m encontram-se nos Tabuleiros costeiros. Nesta região notam-se pequenas mudanças morfoestruturais, com a ocorrência de topos tabulares, capeados por sedimentos do Grupo Barreiras.

Mais ao oeste, nas cotas de 100 a 300 m estão os Tabuleiros pré-litorâneos e os Tabuleiros do rio Pardo, ambos sustentados sobre as rochas dos Complexos Ibicaraí e Buerarema. Por fim, as cotas de 300 a 1.009 estão localizadas no Planalto Cristalino, especificamente nas Serras e Maciços Pré-Litorâneos, onde predominam serras, alvéolos e depressões intramontanas, tendo como características principais, a presença de montanhas de topos planos e encostas convexas e convexo-côncavas.

Para a análise das classes de declividade, a Bacia do Rio Una foi dividida em cinco unidades, conforme proposta metodológica de Ross (1994), tabela 5 e figura 4. A partir destas delimitações foram possíveis identificar e descrever suas particularidades, relacionando-as com os diferentes tipos de relevos encontrados. Para isso, teve como base as divisões de classes da Embrapa, de acordo com Santos et al. (2005).

A tabela 6 e a figura 4 mostram as classes de declividade calculadas para a BHRU, bem como sua distribuição espacial por tipo de relvo. 


\section{Tabela 6 - Distribuição das classes de declividade e distribuição por tipo de relevo na BHRU}

\begin{tabular}{lcc}
\hline Classes Analisadas & $\mathbf{K m}^{\mathbf{2}}$ & $\mathbf{\%}$ \\
\hline Cobertura detrítica indiferenciada (Ndi) & 2,51 & 0,14 \\
Complexo Buerarema (PP2bg) & 800,67 & 45,49 \\
Complexo Buerarema (PP2bo) & 11,68 & 0,66 \\
Complexo Ibicaraí (A34ie) & 377,35 & 21,44 \\
Corpo de Anuri (PP2 $\lambda a$ ) & 11,65 & 0,66 \\
Depósitos Aluvionares (N4a) & 132,02 & 7,50 \\
Depósitos litorâneos (N4li) & 2,19 & 0,12 \\
Depósitos litorâneos antigos (N3li) & 5,44 & 0,31 \\
Formação Salobro (NP3 E sa (mc) & 48,21 & 2,74 \\
Grupo Barreiras (ENb) & 298,72 & 16,97 \\
Grupo Rio Pardo (NP12pc) & 26,76 & 1,52 \\
Grupo Rio Pardo (NP12pn) & 2,98 & 0,17 \\
Suíte Intrusiva Pau Brasil (PP2y2mp) & 40,12 & 2,28 \\
\hline Total & $\mathbf{1 . 7 6 0 , 3 0}$ & $\mathbf{1 0 0}$ \\
\hline
\end{tabular}

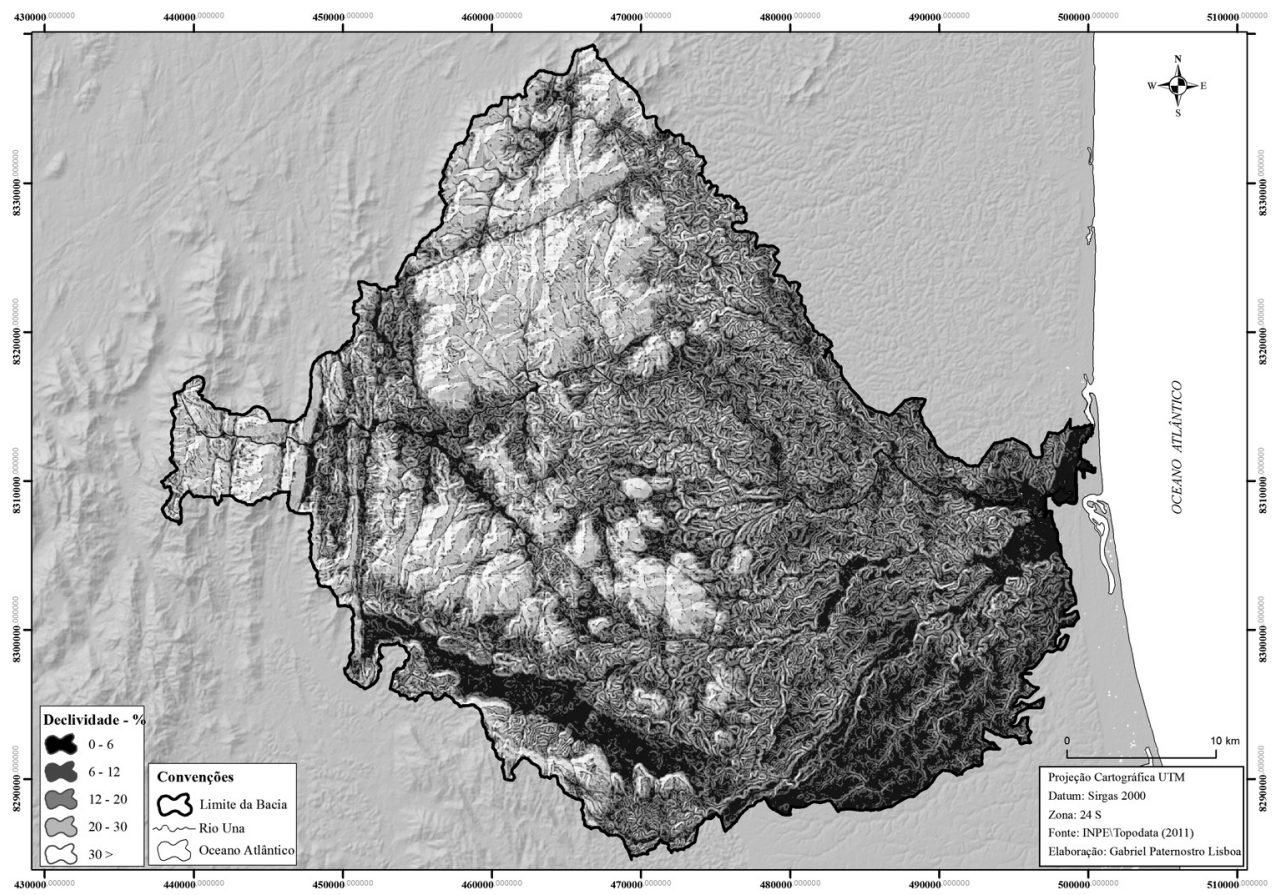

Figura 4 - Mapa de Declividade da Bacia Hidrográfica do Rio Una

Observa-se que a classe de declividade entre 0 e $6 \%$ de inclinação corresponde aos relevos planos a suaves ondulados. Normalmente estas se associam às regiões de acumulações fluviais e marinhas. Já a classe que varia de 6 a 20\% foi encontrada sobre os relevos ondulados, interligados em maior parte sobre os Tabuleiros prélitorâneos. 
As declividades de 20 a $30 \%$ situam-se em superfícies fortes onduladas, tendo como propriedades principais topografias movimentadas, formadas por um conjunto de serras e outeiros, com desníveis acentuados.

Por fim, a última classe mapeada (acima de $30 \%$ ), encontra-se em regiões com relevos fortes ondulados a escarpados. Por apresentar níveis de topografia elevados, na maioria das vezes apresentam montanhas separadas por vales agudos e raramente chatos. Nestas áreas se encontram algumas serras, como a Serra das Lontras, Serra do Lapão e Serra da Onça.

$\mathrm{Na}$ tabela 7 e na figura 5 são apresentadas as classes de substrato rochoso encontradas na BHRU, bem como sua distribuição absoluta, relativa e espacial.

\section{Tabela 7 - Distribuição das classes de substrato rochoso encontradas na BHRU}

\begin{tabular}{lc}
\hline Índices & Valor \\
\hline Área de Drenagem & $1.760,30 \mathrm{~km}^{2}$ \\
Perímetro & $366,54 \mathrm{~km}$ \\
Extensão do Rio Principal & $99,51 \mathrm{~km}$ \\
Extensão Total dos Cursos D'água & $982,79 \mathrm{~km}$ \\
Densidade de Drenagem & $0,56 \mathrm{~km} / \mathrm{km}^{2}$ \\
Coeficiente de Compacidade & 2,45 \\
Fator de Forma & 0,44 \\
Índice de Conformação & 0,46 \\
Sinuosidade do curso principal & 1,65 \\
Declividade do curso principal & $6,53 \mathrm{~m} / \mathrm{km}$ \\
Desnível do curso principal & $650 \mathrm{~m}$ \\
\hline
\end{tabular}

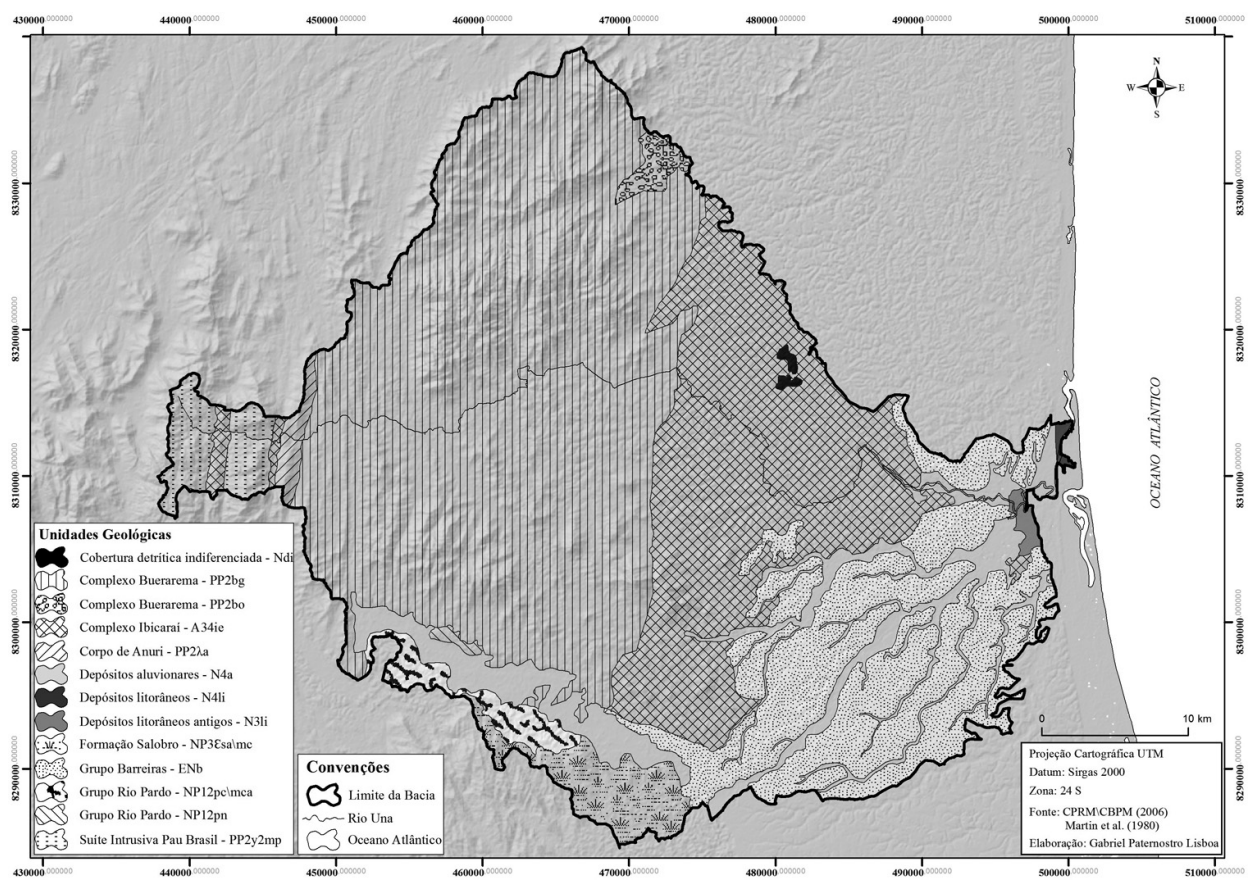

Figura 5 - Mapa do Substrato Rochoso da Bacia Hidrográfica do Rio Una 
Como apresentado na figura 5, a BHRU é dividida em 13 (treze) unidades geológicas, prevalecendo espacialmente às classes: Complexo Buerarema $(46,15 \%)$ e Ibicaraí (21,44\%), Grupo Barreiras (16,97\%) e Depósitos Aluvionares (7,50\%). E cortada por uma Zona de Cisalhamento Transcorrente Sinistral que divide os Complexos Buerarema e Ibicaraí. Além disso, nota-se um elevado número de falhas geológicas, dando destaque para a ruptura localizada próximo ao Parque Nacional Serra das Lontras.

A tabela 8 e a figura 6 mostram as sete unidades pedológicas encontradas na BHRU, bem como sua área absoluta e relativa e distribuição espacial.

\section{Tabela 8 - Distribuição das classes de solos da BHRU}

\begin{tabular}{lcc}
\hline Classe Pedológicas & $\mathbf{k m}^{\mathbf{2}}$ & $\mathbf{\%}$ \\
\hline Argissolo Vermelho - Amarelo Distrófico - (PVAd) & 520,65 & 29,58 \\
Argissolo Vermelho - Amarelo Eutrófico - (PVAe) & 175,96 & 10,00 \\
Espodossolos Humilúvicos Hidromórficos - (EK) & 3,33 & 0,19 \\
Gleissolos Sálicos (Mangues) - (GZ) & 6,17 & 0,35 \\
Latossolo Amarelo Distrófico - (LAd) & 490,53 & 27,86 \\
Latossolo Vermelho - Amarelo Distrófico - (LVAd & 485,09 & 27,56 \\
Neossolos Flúvicos (Aluviais) - (RY) & 78,57 & 4,46 \\
\hline Total & $\mathbf{1 . 7 6 0 , 3 0}$ & $\mathbf{1 0 0}$ \\
\hline
\end{tabular}

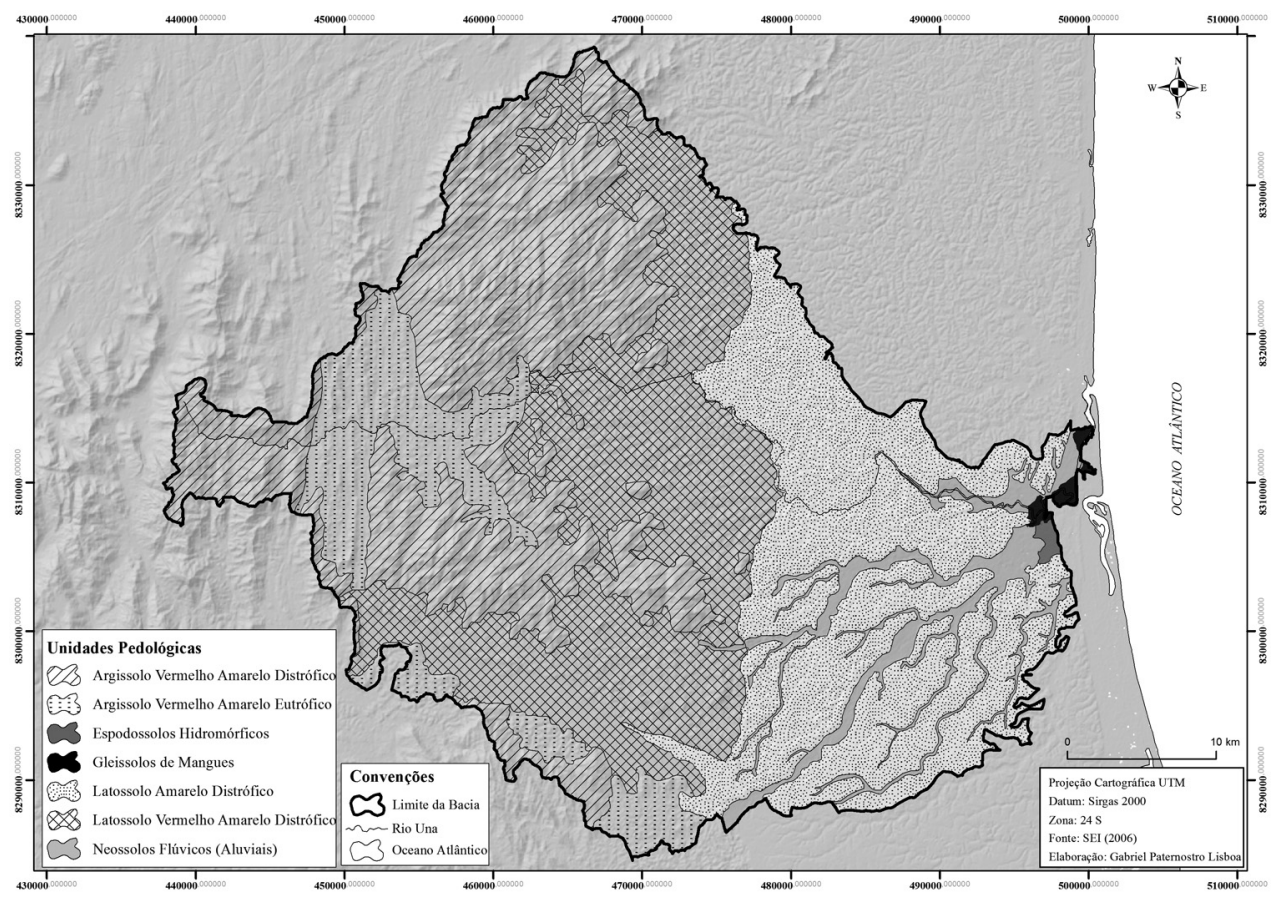

Figura 6 - Mapa de Solos da Bacia Hidrográfica do Rio Una 
$\mathrm{Na}$ área de estudo há o predomínio de Latossolos, espacializados em relevos planos a ondulados. Segundo Santos et al. (2013), estes são solos evoluídos, bem drenados e em avançado estágio de intemperização. Os Argissolos também são encontrados na bacia sobre relevos ondulados a escarpados. São mais suscetíveis aos processos erosivos, devido à própria dissecação do relevo. São solos minerais, com profundidade e drenagem variável. Os Neossolos Flúvicos ocorrem próximos aos cursos d'água, visto que são derivados de sedimentos aluviais e constituídos por material mineral ou orgânico pouco espesso; logo são solos jovens, com drenagem imperfeita (SANTOS et al., 2013).

Por fim, as últimas unidades mapeadas foram os Gleissolos Sálicos e os Espodossolos Humilúvicos. A primeira se caracteriza por apresentar solos mal drenados, encontrados em áreas de mangue situados próximo ao distrito de Pedra de Una. Já a segunda localiza-se próximo a confluência do Rio São Pedro com o Rio Una em um terraço arenoso. Em geral, são solos pouco férteis devido à baixa reserva de nutrientes.

Na tabela 9 estão apresentadas as classes de uso e ocupação do solo identificadas na bacia, bem como suas áreas absoluta e relativa.

\section{Tabela 9 - Distribuição das classes de uso e ocupação} do solo da BHRU

\begin{tabular}{lcc}
\hline Classes de Uso do Solo & $\mathbf{K m}^{\mathbf{2}}$ & $\mathbf{\%}$ \\
\hline Pasto\Solo Exposto & 456,77 & 25,95 \\
Remanescentes Florestais & 809,47 & 45,99 \\
Sistema Agroflorestal - Cacau Cabruca & 423,89 & 24,08 \\
Cultivos Diversos & 43,01 & 2,44 \\
Áreas Úmidas & 11,96 & 0,68 \\
Manguezais & 4,95 & 0,28 \\
Áreas Urbanizadas & 3,78 & 0,21 \\
Sem Classificação & 6,47 & 0,37 \\
\hline Total & $\mathbf{1 . 7 6 0 , 3 0}$ & $\mathbf{1 0 0}$ \\
\hline
\end{tabular}

Destaca-se que apesar das constantes mudanças no uso e ocupação do solo, a bacia apresenta uma vasta área de remanescentes florestais, além de cacauais. Como exemplo tem-se as áreas associadas às classes de altas declividades, situadas na região noroeste e centro-oeste da bacia.

Verifica-se que a classe de pasto/solo exposto, corresponde à outra classe com grande representatividade na BHRU, principalmente na parte leste/sul da bacia e está correlacionada aos ambientes antropizados. Constata-se também, que os ambientes com solos encharcados apresentam uma menor distribuição espacial. No entanto, destaca-se a área alagada localizada ao oeste do município de Santa Luzia e os manguezais.

Outras classes mapeadas foram às zonas urbanizadas e os cultivos diversos, figura 7. Os núcleos urbanos identificados correspondem às sedes dos municípios de Una, Arataca, São José da Vitória e Santa Luzia, e os distritos de Pedras de Una, Colônia de Una, Itatingui, Anuri e Nova Betânia. Já os cultivos diversos estão associados às plantações de Piaçava, Coco-da-Baía, Seringa, Banana e Café. 


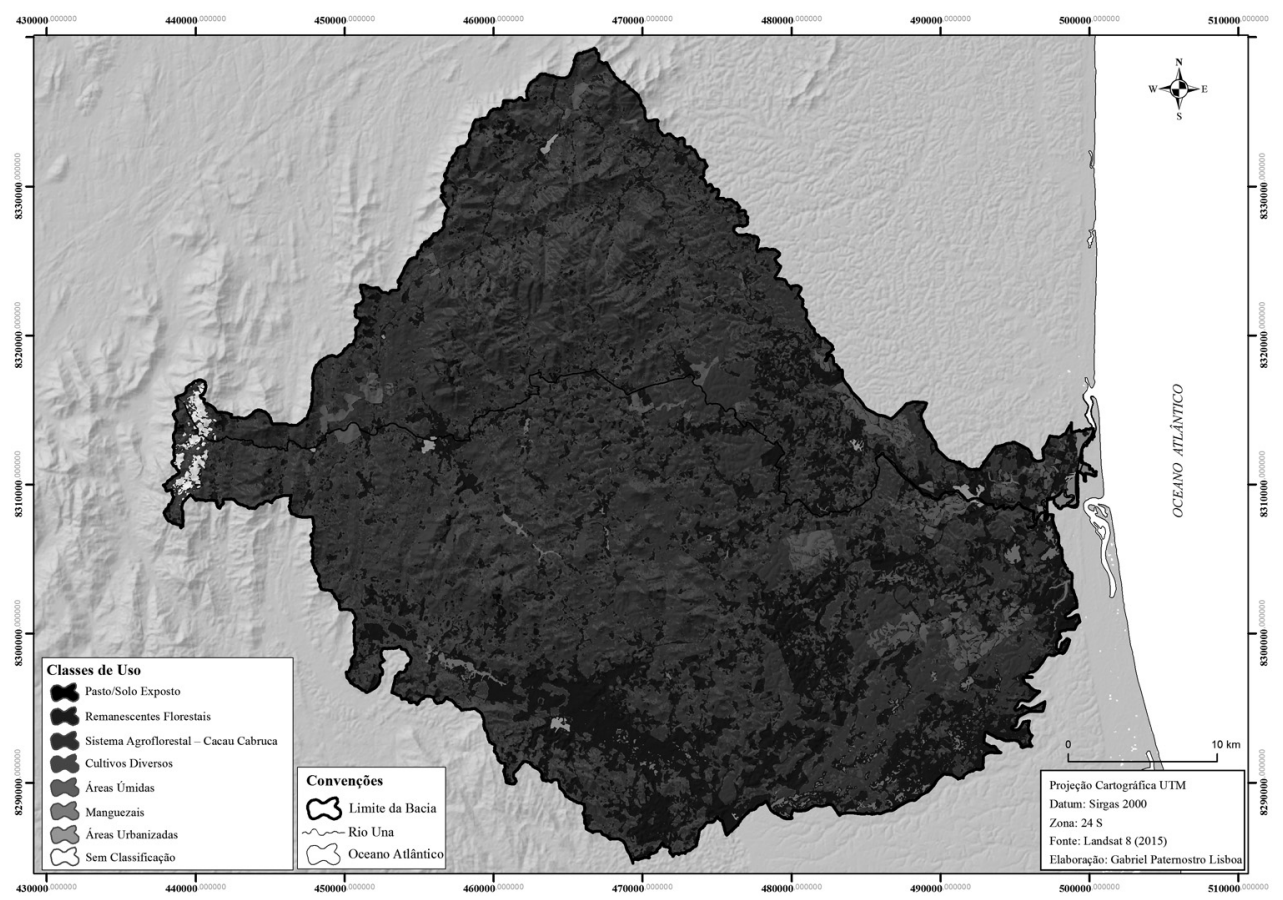

Figura 7 - Mapa de Uso e Ocupação do Solo da Bacia Hidrográfica do Rio Una

\section{Avaliação das fragilidades natural e ambiental da BHRU}

A fragilidade natural da BHRU (Tabela 10) foi obtida a partir do estudo da dinâmica do meio físico, considerando-se os processos formadores da estrutura geológica, pedológica, geomorfológica e climática. Através da correlação destes dados, foi possível avaliar as condicionantes que influenciam e relacionam-se para a ocorrência de processos erosivos.

\section{Tabela 10 - Classes e índices de fragilidade natural calculados para a BHRU}

\begin{tabular}{lccc}
\hline Classes de Fragilidade & Índice de Fragilidade & Área $\left.\mathbf{( k m}^{\mathbf{2}}\right)$ & Área (\%) \\
\hline Fraca a Média & $2-3$ & 986,84 & 56,06 \\
Média a Alta & $3-4$ & 768,69 & 43,67 \\
Alta a Muito Alta & $4-5$ & 4,77 & 0,27 \\
\hline Total & - & $\mathbf{1 7 6 0 , 3 0}$ & $\mathbf{1 0 0}$ \\
\hline
\end{tabular}

Como se observa na tabela 10 e na figura 9, na Bacia do Rio Una, pode-se identificar três classes de fragilidade natural: fraca a média, com índices de fragilidade variando de 2 a 3; média a alta, com índices de 3 a 4 e alta a muito alta, com índices que apresentaram uma variação de 4 a 5. 


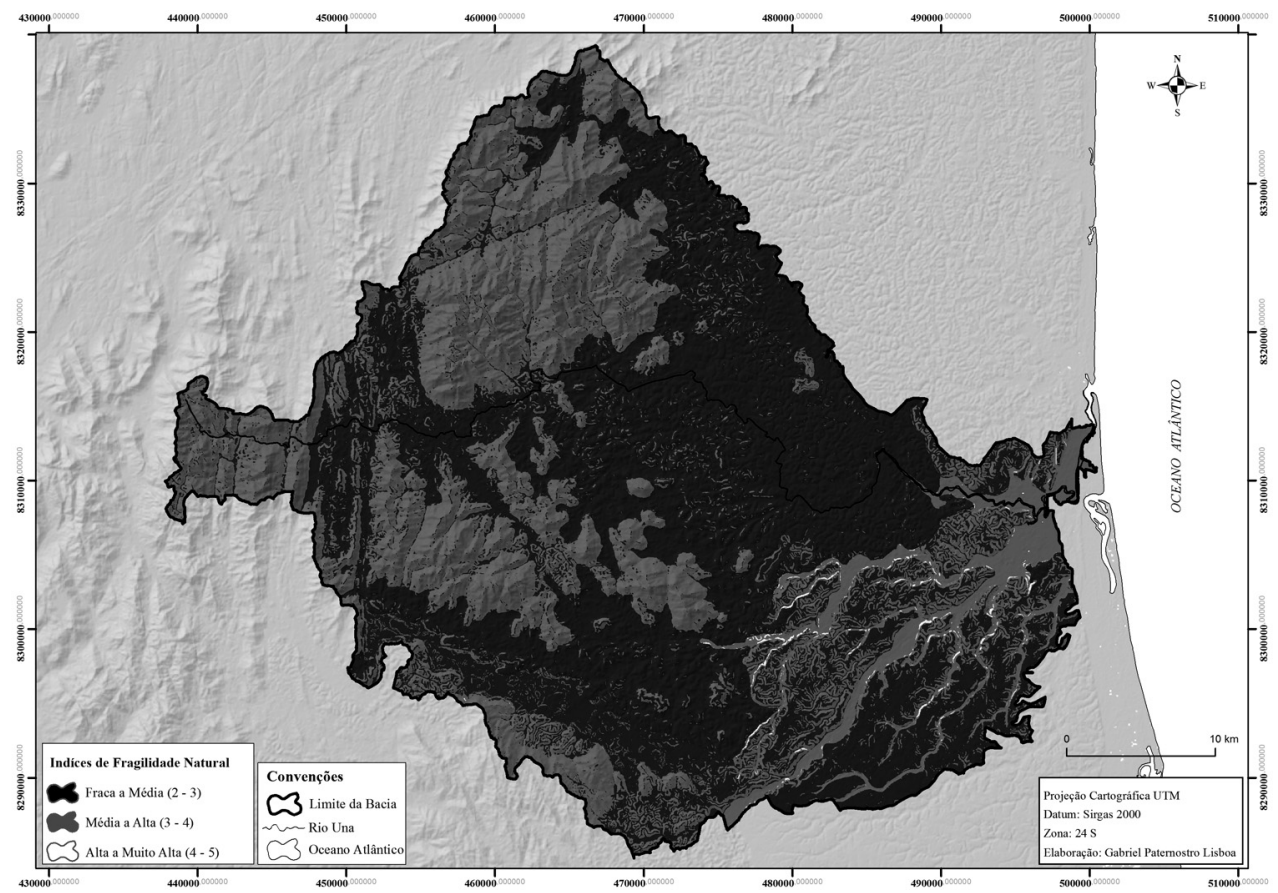

Figura 8 - Mapa de Fragilidade Natural da Bacia Hidrográfica do Rio Una

A análise da figura 8 mostra que a bacia possui três zonas distintas de fragilidade natural. A zona de menor fragilidade natural (fraca a média) está correlacionada ao relevo plano e relevo plano ondulado, aos solos menos friáveis e aos substratos rochosos menos suscetíveis às ações morfogenéticas do relevo.

As zonas de fragilidade média a alta estão correlacionadas aos tabuleiros e planaltos pré-litorâneos, em ambientes com relevo forte ondulado a escarpado. E também, à planície costeira e regiões de acumulação fluvial, formadas por sedimentos com elevado grau de suscetibilidade à erosão.

A zona da bacia que apresenta mair fragilidade natural (alta a muito alta) corresponde aos vales dos rios Salobro e São Pedro que apresentam solos de baixa fertilidade e um substrato rochoso bem mais suscetível.

Para a determinação das classes de fragilidade ambiental da Bacia do Rio Una (tabela 11 e figura 9), além dos componentes físicos, considerou-se o uso e ocupação do solo. Como se observa na tabela 11, a partir da inclusão das formas de uso e ocupação do solo, houve um aumento no número de classes de fragilidade: muito fraca a fraca, com índices de fragilidade variando de 1 a 2; fraca a média, com índices de 2 a 3; média a alta, com índices de 3 a 4 e alta a muito alta que apresentaram uma variação de 4 a 5 quanto aos índices de fragilidade ambiental. 


\section{Tabela 11 - Classes e índices de fragilidade ambiental calculados para a BHRU}

\begin{tabular}{lccc}
\hline Classes de Fragilidade & Índice de Fragilidade & Área $\mathbf{( k m}^{\mathbf{2}} \mathbf{)}$ & Área (\%) \\
\hline Muito Fraca a Fraca & $1-2$ & 626,37 & 35,58 \\
Fraca a Média & $2-3$ & 611,55 & 34,74 \\
Média a Alta & $3-4$ & 371,62 & 21,11 \\
Alta a Muito Alta & $4-5$ & 144,29 & 8,20 \\
Sem Classificação & - & 6,47 & 0,37 \\
\hline Total & - & $\mathbf{1 7 6 0 , 3 0}$ & $\mathbf{1 0 0}$ \\
\hline
\end{tabular}

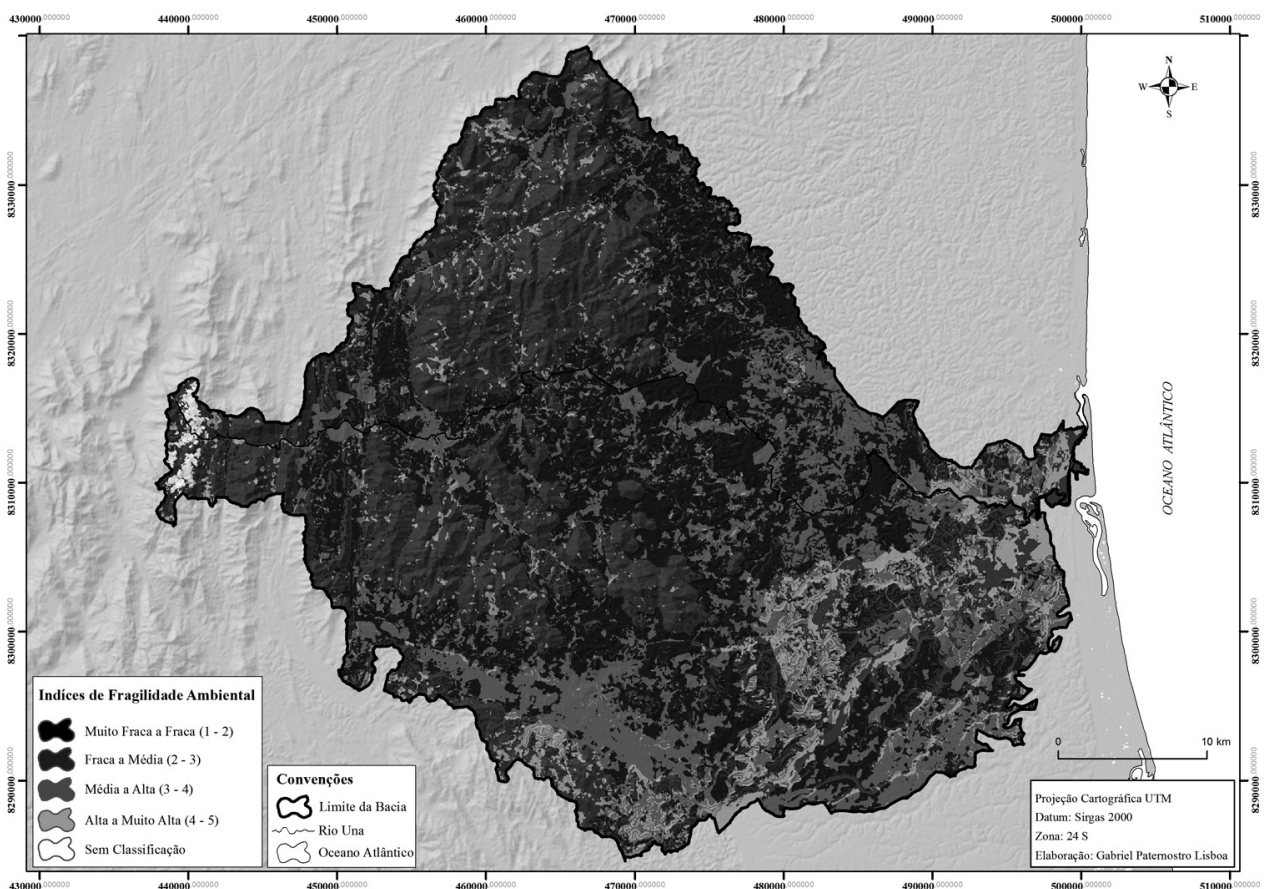

Figura 9 - Mapa de Fragilidade Ambiental da Bacia Hidrográfica do Rio Una

A análise da figura 9 mostra a distribuição espacial dessas classes de fragilidade ambiental na BHRU. A classe de menor fragilidade ambiental (muito fraca a fraca) se distribui por toda a bacia, em ambientes com formações florestais interligados a sistemas naturais menos suscetíveis a eventos erosivos.

A classe de fragilidade ambiental fraca a média está relacionada às paisagens com cobertura vegetal, contudo, em decorrência do grau de dissecação do relevo, estas se apresentam mais frágeis. É possível notar a presença destas áreas na parte central da BHRU e nas zonas oeste e noroeste.

A classe de fragilidade ambiental média a alta corresponde às áreas que apresentaram fragilidade natural fraca a média, entretanto, com a introdução de ativida- 
des agropecuárias na bacia, sem um manejo adequado e, o avanço da urbanização, estas áreas têm-se mostrado mais vulneráveis à erosão. Como exemplo tem-se as áreas localizadas sobre sedimentos terciários do Grupo Barreiras e àquelas associadas aos substratos dos depósitos aluvionares nos tabuleiros do rio Pardo.

A classe de maior fragilidade ambiental (alta a muito alta) se concentra nas porções leste e sul da bacia. O que configura tal classe são os usos excessivos da terra em localidades onde o equilíbrio dinâmico da natureza favorece os processos transformadores do ambiente como a morfogênese; implicando numa maior instabilidade dessas áreas.

\section{CONCLUSÃO}

De forma geral, constatou-se que a bacia estudada possui $29,31 \%$ de seu território com indices de fragilidade variando de média a muito alta. Dentro desta classe, as Planícies Costeiras, Regiões de Acumulações e parte dos Tabuleiros Costeiros, apresentaram-se mais frágeis em decorrência do aumento de ambientes antropizados associados a solos e substratos mais suscetíveis aos processos erosivos. Já os Domínios Geomorfológicos das Serras e Maciços Pré-Litorâneos, apesar de estarem situados em locais com topografias acentuadas, possuem um maior grau de proteção ambiental devido suas encostas estarem ainda cobertas por remanescentes de mata nativa e sistemas agroflorestais (cacau cabruca).

Neste contexto, é notório que nas regiões Centro-Oeste e Noroeste a declividade e a vegetação foram determinantes para a fragilidade dos sistemas. Porém, em se tratando de ambientes próximos ao litoral, as classes pedológicas e litológicas foram mais decisivas, em função da presença de solos arenosos e mal drenados sustentados sobre sedimentos inconsolidados.

Por fim, espera-se que a pesquisa seja uma contribuição para o Comitê das Bacias Hidrográficas do Leste, onde as informações levantadas servirão como subsídios para o planejamento e a gestão da área, com vistas a um desenvolvimento mais sustentável.

\section{REFERÊNCIAS}

ALVARES, C. A et al. Koppen's climate classification map for Brazil. Meteorologische Zeitschrift, Stuttgart/BW - Germany, v. 22, n. 6, p. 711-728. 2013.

BARRETO, A. C et al. Fracionamento Físico e Químico do Carbono Orgânico Total em um Solo de Mata Submetido a Diferentes Usos. Revista Brasileira de Ciências do Solo, Viçosa, v. 32, n. 4, p. 1471 - 1478, 2008.

CHRISTOFOLETTI, A. Geomorfologia. São Paulo: Edgard Blücher, 1 ed., 1974. 149p. DI LUZIO, M. et al. Arcview Interface for Swat 2000. User's Guide. Temple: Blackland Research Center, Texas Agricultural Experiment Station, 345 p., 2002.

GOMES, R. L. Avaliação da Fragilidade Ambiental e Vulnerabilidade Natural à Perda de Solo da Bacia Hidrográfica do Rio Almada - Bahia. Boletim Geográfico, Maringá, v. 31, n. 3 , p. $41-53,2013$. 
ROSS, J. L. S. Análise Empírica da Fragilidade dos Ambientes Naturais e Antropizados. Revista do Departamento de Geografia/USP. São Paulo - SP, n 8, p. 63 - 74, 1994.

SAMBUICH, R. et al. Cabruca agroforest in Southern Bahia, Brazil: tree componente, management practices and tree species conservation. Biodiversity and Conservation, v. 21, n. 4, p. 1055-1077, 2012.

SANTOS, H. G. et al. Sistema Brasileiro de Classificação de Solos. Brasília, DF: Embrapa, 3 ed., 2013. 353p.

SANTOS et al. Manual de Descrição e Coleta de Solo no Campo. Revista da Sociedade Brasileira de Ciência de Solo, Viçosa, 5 ed., 2005, 100p.

SOLLBERG, I.; SCHIAVETTI, A.; MORAES, M. E. B. Manejo agrícola no Refúgio de vida Silvestre de Una: agroflorestas como uma perspectiva de conservação. Revista Árvore, Viçosa, v. 38, n. 2, p. 241-250, 2014.

STRAHLER, A. N. Quantitative geomorphology of drainage basins and channel networks. In: CHOW, V.T. (Ed.). Handbook of Applied Hydrology, New York - EUA: McGrawHill Education, 1964. p. 439 - 476.

THOMAS, W.W. CARVALHO, A.M.V. AMORIM, A.M.A. GARRISON, J. ARBELÁES, A.A.L. Plant endemism in two forests in southern Bahia, Brazil. Biodiversity and Conservation, v. 7, n. 3, p. 11-322, 1998.

TRICART, J. Ecodinâmica. Rio de Janeiro - RJ: IBGE/SUPREN, 1977. 91p.

WALDBURGUER, T. Zoneamento Geoambiental da Zona Costeira dos Municípios de Maraú e Camamu - BA. 2014. 60p. Dissertação (Mestrado em Desenvolvimento Regional e Meio Ambiente) - Universidade Estadual de Santa Cruz, Ilhéus - BA, 2014.

Recebido em maio de 2016

Revisado em julho de 2016

Aceito em fevereiro de 2017 